\title{
10 Activity participation policy
}

\author{
Philip Ward
}

\section{How to use this policy}

Physical activity participation is an essential contributor towards mental health, which is viewed as a multifaceted state of wellbeing. Depression and anxiety symptoms are indicators of poor mental health, whilst selfesteem and self-concept are potential hallmarks of good mental health (Ahn \& Fedewa, 2011). Encouraging physical activity is a form of mental health promotion, and the school environment provides an important opportunity to communicate the health benefits of participation in physical activity, both during attendance at school and in daily family life. This policy example is intentionally broad and school policy creators are encouraged to delete and build upon suggestions below to create a policy that best represents their school.

Policies related to activity participation should have five main goals:

1. To promote autonomous regulation. Self-determination theory suggests that long-term participation in physical activity is most likely to be sustained when an individual adopts autonomous regulation and where behaviour reflects personal interests and values (e.g., "I enjoy playing football with my friends during the lunch break"). This contrasts with non-autonomous regulation, where an individual feels constrained to adopt behaviour due to external pressures (e.g., "I don't really enjoy doing calisthenics during physical education classes, but I do it because it is compulsory"). Schools that prioritise sports or reward and praise one activity over another will lessen the likelihood of a student's achieving autonomous regulation in relation to structured physical activity.

2. To ensure barriers to physical activity participation are minimised for all students. It is important to ensure that all students are able to participate in school-based physical activity programs. Physical or intellectual disability should not be a barrier to participation, with appropriate adjustment of skill level requirements. Emphasis should be placed on enhancing individual performance over time, rather than merely focussing on performance relative to others. 
3. To enhance physical activity outside of scheduled sport and exercise classes. Although organised sport and exercise classes provide an obvious means to increase physical activity, there are other opportunities that can be used to increase physical activity participation for students who do not wish to participate in individual or team sports. Non-exercise-related physical activity can also build fitness, and this can then make it easier for students to participate in sporting activities.

4. To encourage adults to model positive behaviour to enhance physical activity participation. Although some staff members have particular expertise in physical education, promoting physical activity participation should be an important goal for the whole school community. Thus, when schools implement an activity participation policy, they should provide opportunities for school staff and parents to model physical activity to students.

5. To reduce sedentary time. Reducing the amount of time students are sedentary is beneficial in addition to encouraging more physical activity. There is clear evidence that reducing sedentary time (time spent sitting) produces substantial health benefits independent of how much structured physical activity (e.g., sport or exercise) people undertake (Owen et al., 2010). Some schools with adequate resources could consider providing students with access to standing desks that enable them to spend part of the school day learning whilst standing.

[To adapt and use this policy, delete or modify the text as indicated]

\section{[INSERT name of school] Activity participation policy}

\section{Rationale}

Physical activity provides multiple benefits for young people. Appropriate practice of physical activity assists:

- Development of healthy bones, muscles and joints;

- Development of cardiorespiratory fitness;

- Development of better coordination and movement control;

- In maintaining a healthy body weight, in combination with a healthy diet.

Physical activity also provides important benefits for mental wellbeing and can reduce the impact of mental illnesses, including depression and anxiety (Biddle et al., 2018; Dale et al., 2019). In addition, increased physical activity can prevent anxiety and depression (Schuch et al., 2018; 2019). In addition, participation in physical activity can assist in the social development of young people by providing opportunities for self-expression, building self-confidence, social interaction and integration. It has also been suggested that physically active young people more readily adopt other healthy behaviours (e.g., avoidance of tobacco, alcohol and drug use) and demonstrate high academic 
performance at school, although such benefits may be subject-specific and differ between girls and boys (Ludyga et al., 2020). The type, context, frequency, duration and intensity of physical activity will also impact mental health and academic performance outcomes.

\section{Purpose}

This policy outlines the benefits of physical activity participation for students and key factors that will enhance students' school-based participation in physical activity.

\section{Scope}

This policy applies to all students, and to ensure maximum impact, staff from the school should also be encouraged to take part in physical activity programs.

[INSERT specific roles and responsibilities of individuals or teams]

\section{Policy statement}

We believe that the best exercise is the one that you enjoy.

At [INSERT name of school] we encourage students to make their own decision over exercise participation.

At [INSERT name of school] we help students identify the types of physical activity they enjoy and develop the skills that will enhance performance and mastery of their chosen activity or sport.

At [INSERT name of school] there is no type of physical activity that is compulsory for all students.

Staff at [INSERT name of school] acknowledge the benefits of participation in all sport. We therefore do not reward and praise engagement in the performance of one sport over another. Thus, all sport participation is welcomed and one particular skill set (e.g., ball skills in football or tennis) is not prioritised over another (e.g., skateboarding).

At [INSERT name of school] we endeavour to ensure that all students are able to participate in school-based activity programs, irrespective of their skill set.

We recognise that some students will excel at sports; however, we understand that it is critical that all students are provided with opportunities to try different sports and activities to enable them to find what works for them.

Our staff understand that non-participation is a sign that a student has not yet found the right activity, not that they are bad at sports.

At [INSERT name of school] we look for alternative ways for students to participate in physical activity beyond organised sport, for example, walking or cycling to school, and encouraging the use of stairs rather than elevators.

School staff and adult family members of the [INSERT school name] community promote the importance of physical activity participation in students. 


\section{Ward}

We encourage school-wide activities such as cross-country running or step challenges where everyone participates, including the professional school leadership, administrative and custodial staff, to help reinforce the message that physical activity participation is for everyone, not just elite athletes. Likewise, we encourage parents to model positive behaviours related to physical activity.

At [INSERT name of school] we take steps during the course of a school day to discourage sedentary behaviours. Students are therefore encouraged to break up long periods of sitting, using mini-breaks to stand and stretch.

\section{Rating of evidence base}

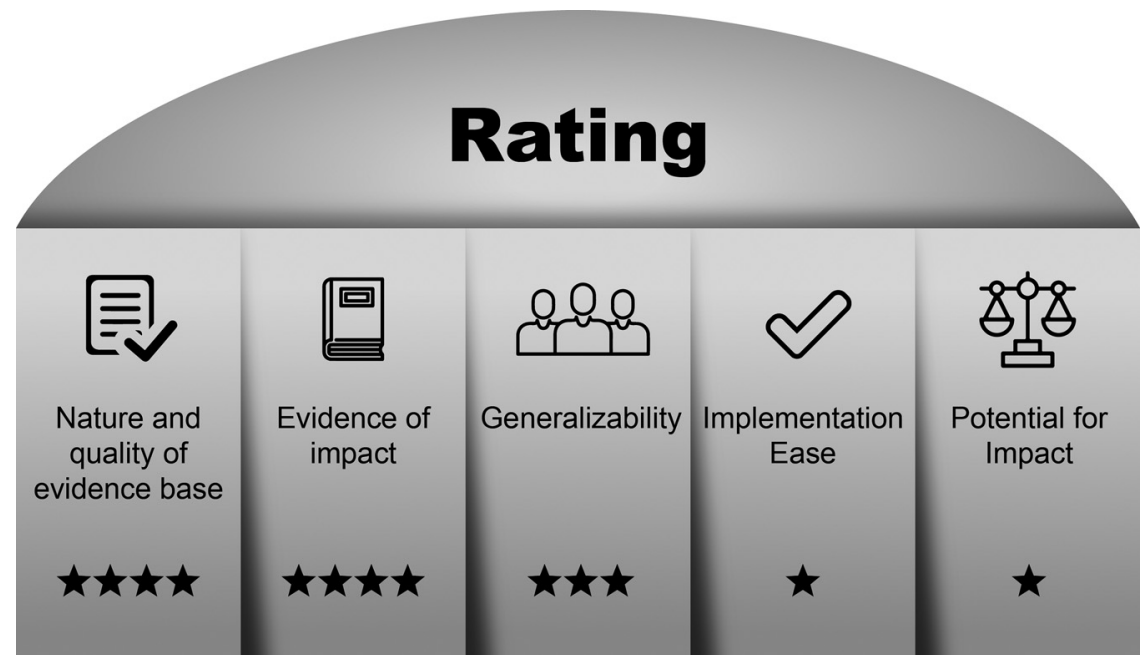

Figure 10.1. Activity Participation Rating of Evidence.

Author Note. The literature represents a large body of evidence with clear positive benefits. It is well established that even modest changes in physical activity provide substantial physical and mental health benefits. In respect to generalisability, there have been studies conducted in many settings, although fewer have been undertaken in low- and middle-income countries. Many of the recommendations in this policy can be implemented with little or no cost. There is excellent potential for impact, as establishing good physical activity habits in youth will likely lead to these positive behaviours being adopted over the lifespan.

\section{Authorship}

Professor Philip Ward, School of Psychiatry, UNSW Sydney [INSERT RELEVANT STAFF MEMBERS] 


\section{Related policy and documents}

\section{[INSERT RELEVANT POLICY AND DOCUMENTS]}

Mountjoy, M., Andersen, L. B., Armstrong, N., Biddle, S., Boreham, C., Bedenbeck, H.-P. B., \& van Mechelen, W. (2011). International Olympic Committee consensus statement on the health and fitness of young people through physical activity and sport. British Journal of Sports Medicine, 45(11), 839.

Vanderloo, L. M., Cairney, J., Choquette, L., Collet, J. P., Davies, T., Faulkner, G., et al. (2018). Expert statement on physical activity and brain health in children and youth. https://www.participaction.com/sites/default/files/downloa ds/expert_statement_ on_physical_activity_and_brain_health_in_children_a nd_youth.pdf/

\section{Date of ratification}

This policy was ratified on the [INSERT DATE].

\section{Date of review}

This policy will be reviewed by [INSERT DATE].

\section{Further reading}

Faulkner, G., \& Duncan, M. (2018). Physical activity and mental health: A focus on de- pression. In J. Piggin, L. Mansfield, \& M. Weed (Eds.), Routledge handbook of physical activity policy and practice (pp. 171-185). Abingdon: Routledge. Tremblay, M. S., Carson, V., Chaput, J., Connor Gorber, S., Dinh, T., Duggan, M., ... Poitras, V. J. (2016). Canadian 24-hour movement guidelines for children and youth: An integration of physical activity, sedentary behaviour, and sleep. Applied Physiology Nutrition and Metabolism, 41, S311-S327.

\section{Expert consultation}

School administrators will need to discuss implementation procedures with specialist physical education staff, and ensure counsellors are aware of important health benefits of physical activity in preventing or reducing symptoms of common mental disorders, such as depression and anxiety.

\section{References}

Ahn, S., \& Fedewa, A. L. (2011). A meta-analysis of the relationship between children's physical activity and mental health. Journal of Pediatric Psychology, 36(4), 385-397. 


\section{Ward}

Biddle, S. J. H., Ciaccioni, S., Thomas, G., \& Vergeer, I. (2018). Physical activity and mental health in children and adolescents: An updated review of reviews and an analysis of causality. Psychology of Sport and Exercise, 42, 146-155.

Dale, L. P., Vanderloo, L., Moore, S., \& Falkner, G. (2019). Physical activity and depression, anxiety, and self-esteem in children and youth: An umbrella systematic review. Mental Health and Physical Activity, 16, 66-79.

Ludyga, S., Gerber, M., Pühse, U., Looser, V. N., \& Kamijo, K. (2020). Systematic review and meta-analysis investigating moderators of long-term effects of exercise on cognition in healthy individuals. Nature Human Behaviour, 4(6), 603-612.

Owen, N., Sparling, P. B., Healy, G. N., Dunstan, D. W., \& Matthews, C. E. (2010). Sedentary behavior: emerging evidence for a new health risk. Mayo Clinic Proceedings, 85(12), 1138-1141.

Schuch, F. B., Vancampfort, D., Firth, J., Rosenbaum, S., Ward, P. B., Silva, E. S., Hallgren, M., Ponce De Leon, A., Dunn, A. L., Deslandes, A. C., Fleck, M. P., Carvalho, A. F., \& Stubbs, B. (2018). Physical activity and incident depression: A meta-analysis of prospective cohort studies. The American Journal of Psychiatry, 175(7), 631-648.

Schuch, F. B., Stubbs, B., Meyer, J., Heissel, A., Zech, P., Vancampfort, D., Rosenbaum, S., Deenik, J., Firth, J., Ward, P. B., Carvalho, A. F., \& Hiles, S. A. (2019). Physical activity protects from incident anxiety: A meta-analysis of prospective cohort studies. Depression and Anxiety, 36(9), 846-858. 